NBER WORKING PAPER SERIES

PRICING ASSETS IN A PERPETUAL YOUTH MODEL

\author{
Roger Farmer \\ Working Paper 24261 \\ http://www.nber.org/papers/w24261 \\ NATIONAL BUREAU OF ECONOMIC RESEARCH \\ 1050 Massachusetts Avenue \\ Cambridge, MA 02138 \\ January 2018
}

I would like to thank Fernando Alvarez, Markus K. Brunnermeir, Zeno Enders, Emmanuel Farhi, Leland E. Farmer, Xavier Gabaix, Nicolae G^arleanu, Valentin Haddad, Lars Peter Hansen, Nobuhiro Kiyotaki, Robert E. Lucas Jr., N. Gregory Mankiw, Stavros Panageas, Nancy L. Stokey, Harald Uhlig, Ivan Werning and Pawel Zabczyk for their comments on earlier versions of the ideas contained in this paper. I would especially like to thank Leland E. Farmer for detailed and insightful comments. Thanks also to an anonymous referee of this journal and to the editor, Vincenzo Quadrini, who made a number of important suggestions that considerably improved the final version of the paper. I would also like to thank participants at the NBER Economic Fluctuations and Growth Meeting in February of 2014, the NBER 2014 summer workshop on Asset pricing, the 2014 summer meetings of the Society for Economic Dynamics in Toronto Canada, and the Brigham Young University Computational Public Economics Conference in Park City Utah, December 2014. Earlier versions of this work were presented at the Bank of England, the Board of Governors of the Federal Reserve, Harvard University, the International Monetary Fund, the Barcelona GSE 2015 Summer Forum, the London School of Economics, the London Business School, Penn State University, the University of Chicago, the Wharton School and Warwick University. Thanks to C. Roxanne Farmer for her editorial assistance. The views expressed herein are those of the author and do not necessarily reflect the views of the National Bureau of Economic Research.

NBER working papers are circulated for discussion and comment purposes. They have not been peer-reviewed or been subject to the review by the NBER Board of Directors that accompanies official NBER publications.

(C) 2018 by Roger Farmer. All rights reserved. Short sections of text, not to exceed two paragraphs, may be quoted without explicit permission provided that full credit, including () notice, is given to the source. 
Pricing Assets in a Perpetual Youth Model

Roger Farmer

NBER Working Paper No. 24261

January 2018

JEL No. E0,G1

\section{ABSTRACT}

This paper constructs a general equilibrium model where asset price fluctuations are caused by random shocks to beliefs about the future price level that reallocate consumption across generations. In this model, asset prices are volatile, and price-earnings ratios are persistent, even though there is no fundamental uncertainty and financial markets are sequentially complete. I show that the model can explain a substantial risk premium while generating smooth time series for consumption. In my model, asset price fluctuations are Pareto inefficient and there is a role for treasury or central bank intervention to stabilize asset price volatility.

\section{Roger Farmer}

UCLA

Department of Economics

Box 951477

Los Angeles, CA 90095-1477

and NBER

rfarmer@econ.ucla.edu 


\title{
Pricing Assets in a Perpetual Youth Model
}

\author{
By Roger E.A. FARMER*
}

\begin{abstract}
This paper constructs a general equilibrium model where asset price fluctuations are caused by random shocks to beliefs about the future price level that reallocate consumption across generations. In this model, asset prices are volatile, and price-earnings ratios are persistent, even though there is no fundamental uncertainty and financial markets are sequentially complete. I show that the model can explain a substantial risk premium while generating smooth time series for consumption. In my model, asset price fluctuations are Pareto inefficient and there is a role for treasury or central bank intervention to stabilize asset price volatility.
\end{abstract}

A large literature in finance seeks to reconcile features of financial data with features of aggregate time series (Gabaix, 2012). Typically, these explanations combine some version of the rare disasters hypothesis of Rietz (1988) and Barro (2006) with the variable long-run risk model of Bansal and Yaron (2004). To successfully explain financial data in an equilibrium model, the theorist must explain why the price of risk is highly volatile, while consumption data are smooth.

Most equilibrium explanations of financial data are based on the assumption that all shocks to the economy are fundamental. For example, in the long-run risk model of Bansal and Yaron (2004), consumption growth is exogenous and has a small highly persistent component. In the rare disaster model of Rietz (1988) and Barro (2006) there is, occasionally, a large negative shock to the aggregate endowment.

This paper explores an alternative approach. I build on the work of David Cass and Karl Shell (1983), by constructing a model where asset price fluctuations are caused by non-fundamental shocks to people's beliefs. Cass and Shell presented

\footnotetext{
* Farmer: Department of Economics, University of Warwick, National Institute of Economic and Social Research, and UCLA, rfarmer@econ.ucla.edu. I would like to thank Fernando Alvarez, Markus K. Brunnermeir, Zeno Enders, Emmanuel Farhi, Leland E. Farmer, Xavier Gabaix, Nicolae Gârleanu, Valentin Haddad, Lars Peter Hansen, Nobuhiro Kiyotaki, Robert E. Lucas Jr., N. Gregory Mankiw, Stavros Panageas, Nancy L. Stokey, Harald Uhlig, Ivan Werning and Pawel Zabczyk for their comments on earlier versions of the ideas contained in this paper. I would especially like to thank Leland E. Farmer for detailed and insightful comments. Thanks also to an anonymous referee of this journal and to the editor, Vincenzo Quadrini, who made a number of important suggestions that considerably improved the final version of the paper. I would also like to thank participants at the NBER Economic Fluctuations and Growth Meeting in February of 2014, the NBER 2014 summer workshop on Asset pricing, the 2014 summer meetings of the Society for Economic Dynamics in Toronto Canada, and the Brigham Young University Computational Public Economics Conference in Park City Utah, December 2014. Earlier versions of this work were presented at the Bank of England, the Board of Governors of the Federal Reserve, Harvard University, the International Monetary Fund, the Barcelona GSE 2015 Summer Forum, the London School of Economics, the London Business School, Penn State University, the University of Chicago, the Wharton School and Warwick University. Thanks to C. Roxanne Farmer for her editorial assistance.
} 
this idea in a two-period real model. I show that a calibrated version of their model can explain real world data.

I construct a general equilibrium model where asset price fluctuations are caused by random shocks to beliefs about the future price level that reallocate consumption across generations. In this model, asset prices are volatile and price-earnings ratios are persistent even though there is no fundamental uncertainty and financial markets are sequentially complete. Because I am interested in the ability of non-fundamental shocks to explain asset prices, my model has no fundamental uncertainty of any kind.

I refer to the random variable that drives asset prices in equilibrium as a belief shock and I refer to the mapping from belief shocks to realizations of the price level as a belief function (Farmer, 1993). I treat belief shocks and the belief function as new fundamentals that select one of the many possible equilibria of the underlying monetary model.

My work differs in three ways from standard asset pricing models. First, I allow for birth and death by exploiting Blanchard's (1985) concept of perpetual youth. Second, my model contains an asset, government debt, denominated in dollars. Third, there are two types of people that differ in the rate at which they discount the future. The perpetual youth assumption and the existence of a nominal asset are essential to generate volatile asset prices in the presence of sequentially complete asset markets. The assumption of two types of people allows me to construct equilibria where there are active trades in the financial markets by people of different types.

I model a government with two branches; a central bank and a treasury. The central bank operates an interest rate peg and the treasury adjusts the tax rate periodically to ensure the government remains solvent. Because debt is denominated in dollars, this policy leads to indeterminacy of the initial equilibrium price level. For every initial price in a certain set, there is a different allocation of the present value of taxes between current and future generations. For each allocation of taxes, there is a different non-stationary perfect foresight equilibrium price sequence. Each of these sequences converges to the same steady-state equilibrium.

I exploit the indeterminacy of the set of perfect foresight equilibria to construct a rational expectations equilibrium in which non-fundamental shocks cause asset price fluctuations. The people in my model believe the future price level is a random variable, driven by a belief shock, and they write financial contracts contingent on its realization. In equilibrium, their beliefs turn out to be correct. Because the unborn cannot buy or sell contracts traded before they are born, belief shocks have real effects that reallocate resources between people of different generations.

I am pursuing an alternative explanation for asset price fluctuations because I am ultimately interested in a normative question. Should the treasury and or the central bank intervene in asset markets to reduce volatility? If all asset market fluctuations are caused by the responses of a representative agent to un- 
avoidable endowment shocks, the government should not seek to intervene. If instead, a large component of asset price fluctuations is due to Pareto inefficient re-allocations of consumption goods between people of different generations, there is a potential role for an active financial policy, of the kind discussed in Farmer and Zabczyk (2016), to stabilize those fluctuations.

\section{Antecedents}

An active body of scholars seek to explain asset price data using the representative agent model. Some of the modifications to this model that have been tried include richer utility specifications (Abel, 1990; Constantinides, 1990; Campbell and Cochrane, 1999; Bansal and Yaron, 2004) adding technology shocks with exogenous time-varying volatility (Bansal and Yaron, 2004), and assuming that technology is occasionally hit by rare disasters (Rietz, 1988; Barro, 2005, 2006; Wachter, 2013; Gourio, 2012; Gabaix, 2012).

Here, I take an alternative approach. I build on the idea that non-fundamental shocks can have real effects when there is incomplete participation in asset markets. David Cass and Karl Shell (1983) refer to non-fundamental shocks as 'sunspots' and Costas Azariadis (1981) and Roger Farmer and Michael Woodford (1997) call them 'self-fulfilling prophecies'. Although the term 'sunspot' is widely understood by economic theorists, I have found that it represents a source of confusion when explaining the idea to a lay audience and I use the term 'belief shock' in this paper to mean non-fundamental uncertainty that may have real effects.

My work is closely related to four working papers, Farmer (2002a,b, 2014) and Farmer et al. (2012). Farmer (2002b) develops a version of Blanchard's (1985) perpetual youth model with capital and aggregate uncertainty, Farmer (2002a) adds nominal government debt to explain asset price volatility and Farmer et al. (2012) construct a model with multiple types. ${ }^{1}$ The current paper relies on all three of these pieces; perpetual youth, nominal debt and multiple types. ${ }^{2}$

The idea of constructing stationary stochastic rational expectations equilibria by randomizing over multiple steady states is due to Azariadis (1981). The first paper to exploit randomizations across indeterminate perfect foresight paths in a monetary model is by Farmer and Woodford (1997). Farmer et al. (2015) show how to solve models with indeterminacy using standard solution methods by redefining a belief shocks to be a new fundamental and I draw on a non-linear extension of their technique in this paper. In the Farmer-Woodford paper there

\footnotetext{
${ }^{1}$ Farmer et al. (2012) claim to generate equilibria, driven by non-fundamental shocks. That claim is incorrect as their model fails to equate the marginal rates of substitution of each type of agent in every state and consequently, the paper does not fulfill its claim to generate sunspot equilibria. I am grateful to Markus Brunnermeir and Valentin Haddad for discussions on this point.

${ }^{2}$ Two earlier versions of the current paper appeared, one with title "Global Sunspots and Asset Prices in a Monetary Economy" (Farmer, 2015) and one with the title "Pricing Assets in an Economy with Two Types of People" (Farmer, 2016). The current version is different, in a number of important ways from both of these versions and for that reason I have changed the title.
} 
is a single type of person in each generation. As a consequence, there is no active trade in the asset markets which serve simply to determine prices at which people choose not to trade. In contrast, I construct a model with two types in which there are active asset market trades between patient and impatient people.

This is not the only paper to explore heterogeneous-agent models to understand asset pricing data. Challe (2004) generates return predictability in an overlapping generations model and Guvenen (2009) constructs a production economy that he solves computationally. Constantinides and Duffie (1996) exploit crosssection heterogeneity of the income process to show that uninsurable income risk across consumers can potentially explain any observed process for asset prices and Kubler and Schmedders (2011) construct a heterogeneous-agent overlapping generations model with sequentially complete markets. By dropping the rational expectations assumption, they are able to generate substantial asset price volatility. In a related paper, Feng and Hoelle (2014) generate large welfare distortions from sunspot fluctuations.

There is also a sizable literature on excess volatility in asset markets as a consequence of bubbles. Jianjun Miao and Pengfei Wang (2017) provide a theory of rational bubbles in an economy with credit constraints and Miao, Wang and Zhiwei Xu (2015) estimate a related model using Bayesian methods. Gârleanu et al. (2012) build a two-agent life-cycle model where the agents have recursive preferences but a common discount factor and they show that this model generates inter-generational shifts in consumption patterns that they call 'displacement risk'. In a related paper Gârleanu and Panageas (2015) study asset pricing in a continuous time stochastic overlapping generations model. These papers focus on fundamental equilibria and they adopt the common assumption of Epstein-Zin preferences (Epstein and Zin, 1989, 1991).

\section{Structure and Assumptions}

I describe an endowment economy with no fundamental uncertainty in which there are complete financial markets and where money is used as a unit of account. I show that this model has a continuum of non-stationary perfect foresight equilibria in which asset prices are described by a persistent difference equation that converges slowly to a steady state. I construct a set of stationary rational expectations equilibria by randomizing across these equilibria.

\section{A. Structure}

Time proceeds in a sequence of periods indexed by $t=1,2, \ldots \infty$. There are two types of people and a measure 1 of each type. People survive into the subsequent period with age-independent probability, $\pi$, that is the same for each type. A person of type $i \in\{1,2\}$ receives an endowment of $\mu_{i}$ units of a unique consumption good in every period in which he is alive. I refer to the consumption 
good as an apple and I assume that

$$
\mu_{1}+\mu_{2}=1
$$

This assumption implies the aggregate endowment of apples of the people born at date $t$, summed over types, is equal to 1 .

Every period a measure $1-\pi$ of type $i$ people from each generation dies and is replaced by a measure $1-\pi$ of new people of the same type. This assumption implies there is a measure 1 of each type alive in every period and the social endowment of apples is constant and equal to 1.

The claim to a person's endowment can be traded in the financial markets. It is a random sequence of payments that I refer to as a tree. The earnings of a single tree is a stochastic process because its owner may die. The earnings of a unit measure of trees is a deterministic variable, equal to the fraction, $\pi$, of people.

People maximize the present discounted sum of expected future utility, where utility is represented by a homogeneous Von-Neumann Morgenstern utility function, $u_{i}$, discounted by a factor, $\beta_{i}$. I assume that type 1 people are more patient than type 2 people; that is,

$$
0<\beta_{2}<\beta_{1}<1
$$

The assumptions that survival probabilities are age independent and utility functions are homogeneous allows me to summarize the consumption of each type of person by a linear function of their aggregate wealth. The assumption that people have different discount factors allows me to construct an equilibrium with active trade in the financial markets in every period between people of different types. In a model with only one type, it would still be possible to generate belief driven asset price fluctuations, but a model with one type would not capture the significant quantity of private borrowing and lending that we see in the real world.

\section{B. Financial Intermediaries, Annuities, and Life Insurance}

In a model with birth and death one must make an assumption about the dispersion of a person's assets when he dies. I follow Blanchard (1985), by assuming the existence of a perfect annuities market.

Although the endowment is constant, the present value of tax liabilities is a random variable. People alive at date $t$ trade a complete set of financial securities, mediated by a set of financial intermediaries. The assets of financial intermediaries consist of a portfolio of state-contingent one-period consumption loans to type 2 people. Their liabilities consist of state-contingent one-period consumption loans from type 1 people.

In a rational expectations equilibrium, a newly born type 1 person becomes a lender and a newly born type 2 person becomes a borrower. A young type 1 person starts out life by consuming less than his endowment. If he has a long life, a type 1 person eventually consumes more than his endowment as he earns additional income from his accumulated assets. A young type 2 person starts out 
life by consuming more than his endowment. If he has a long life, a type 2 person eventually consumes less than his endowment as he repays his accumulated debts.

In addition to acting as intermediaries between buyers and sellers of financial assets, financial intermediaries provide life insurance to cohorts. The size of the endowment owned by any given cohort shrinks geometrically by a factor $\pi \in(0,1)$ as the members of the cohort die. The present value of the endowment owned by any individual in the cohort is a random variable. Financial intermediaries provide perfect insurance against idiosyncratic shocks to the length of life.

To implement the efficient insurance contract, financial intermediaries offer annuities contracts to savers and life-insurance contracts to borrowers. A saver receives a discount in state $\varepsilon$ when he buys a state-contingent claim to one apple in state $\varepsilon^{\prime}$. That claim costs him $\pi Q\left(\varepsilon, \varepsilon^{\prime}\right)$, where $Q\left(\varepsilon, \varepsilon^{\prime}\right)$ is the price of the claim and $\pi$ is the price of an annuity that pays 1 apple to the financial institution in the event that the person dies and 0 apples if he lives.

On the other side of this market there is a borrower. A borrower receives a loan of $\pi Q\left(\varepsilon, \varepsilon^{\prime}\right)$ in state $\varepsilon$ in return for a promise to repay one apple in state $\varepsilon^{\prime}$. The amount he can borrow against a promise to repay 1 apple is reduced by a fraction, $\pi$. The fraction $\pi$ represents the price of a life-insurance contract that pays the debt of the borrower in the event of his death. Because there are complete markets for aggregate shocks, and because I assume free entry to the financial services industry, financial intermediaries make zero profits in equilibrium.

\section{Financial Markets and Tax Liabilities}

In this subsection I explain the source of uncertainty and I discuss the market structure that allows people to insure against shocks. All shocks in the model arise from non-fundamental shifts in beliefs. In a rational expectations equilibrium, belief shocks are reflected in different realizations of the dollar price of apples that are anticipated by participants in the financial markets. Importantly, newborn people of both types are unable to participate in the financial markets that open before they are born.

Each period, the price level is a function of a publicly observable random variable, $\varepsilon$, drawn from a time-invariant distribution $\chi$ with support $\Omega$. The variable $\varepsilon$ might represent the opinions of the editors of an influential newspaper or the views of a financial journalist. The mapping from $\varepsilon$ to $p$ is common knowledge.

At date $t$, type 1 and type 2 people are aware that prices will fluctuate in period $t+1$ and they trade a complete set of Arrow securities where security $\varepsilon^{\prime}$ is a promise to pay one apple in period $t+1$ if and only if state $\varepsilon^{\prime}$ occurs. I denote the price, at date $t$ in state $\varepsilon$ for delivery of an apple at date $t+1$ in state $\varepsilon^{\prime}$ by $Q\left(\varepsilon, \varepsilon^{\prime}\right)$. I refer to the function $\tilde{Q}\left(\varepsilon, \varepsilon^{\prime}\right) \equiv \frac{Q\left(\varepsilon, \varepsilon^{\prime}\right)}{\chi\left(\varepsilon^{\prime}\right)}$ as the pricing kernel.

The definition of $\tilde{Q}\left(\varepsilon, \varepsilon^{\prime}\right)$ allows me to replace terms of the form

$$
\sum_{\varepsilon^{\prime}} Q\left(\varepsilon, \varepsilon^{\prime}\right) a\left(\varepsilon^{\prime}\right)
$$


where $a\left(\varepsilon^{\prime}\right)$ is an Arrow security that delivers one apple in state $\varepsilon$, and $Q\left(\varepsilon, \varepsilon^{\prime}\right)$ is the price of that security, with conditional expectations,

$$
\mathbb{E}\left[\tilde{Q}\left(\varepsilon, \varepsilon^{\prime}\right) a\left(\varepsilon^{\prime}\right)\right]
$$

where $\tilde{Q}\left(\varepsilon, \varepsilon^{\prime}\right)$ is the pricing kernel.

A price level shock has real effects because it changes the net present value of tax liabilities. A person born into a state with a low price $p$, relative to nominal debt, $B^{N}$, will be born with a high tax liability. Once born, he is perfectly insured against all future fluctuations in $p$. But he cannot insure against the state of the world he is born into. Price fluctuations result in wealth transfers between generations which are translated in equilibrium into persistent fluctuations in the stochastic discount factor.

\section{Government}

There is a government with two branches; a central bank and a treasury. The central bank operates an interest rate peg by standing ready to buy or sell oneperiod dollar-denominated pure-discount bonds for price $\bar{Q}^{N} \cdot{ }^{3} Q^{N}$ is the dollar price of a treasury bond that pays one dollar next period and a policy of fixing $Q^{N}$ is equivalent to setting the money interest rate, $i$, at $i=\frac{1}{Q^{N}}-1$.

The treasury begins the period with debt of $B(\varepsilon)=\frac{B^{N}}{p(\varepsilon)}$, where $B^{N}$ is debt denominated in dollars and $p(\varepsilon)$ is the dollar price of an apple. It operates the tax-transfer policy,

$$
T(\varepsilon)=p(\varepsilon) \tau+(1-\delta) B^{N},
$$

where $\tau$ is a real valued tax or transfer levied on, or distributed equally to, all persons alive at that date. A positive value of $\tau$ denotes a tax and a negative value denotes a transfer. The dollar value of this tax-transfer is equal to $p(\varepsilon) \tau$, where $p(\varepsilon)$ is the dollar price of an apple.

The treasury levies an additional tax of $(1-\delta) B^{N}$, where $B^{N}$ is the outstanding value of government liabilities and $\delta \in[0,1]$. This feature of tax policy represents adjustments to the tax rate made to prevent government debt from becoming too large as a fraction of GDP. ${ }^{4}$

\footnotetext{
${ }^{3}$ Although I model monetary policy, my model is one where no one actually holds money as a means of exchange. Michael Woodford has popularized the idea of modeling what he calls the "cashless limit", Woodford (2003). I adopt that strategy here. Although bonds are denominated in dollars, the dollar serves only as a unit of account.

${ }^{4} \mathrm{An}$ example of a policy of this kind in the real world is the Omnibus Budget Reconciliation Act of 1993, which raised top US marginal tax rates and helped to stabilize the debt to GDP ratio. Before the passage of the Act, the top individual tax rate of $31 \%$ applied to all income over $\$ 51,900$. The Act created a new bracket of $36 \%$ for income above $\$ 115,000$, and $39.6 \%$ for income above $\$ 250,000$.
} 
The real value of government debt follows the equation

$$
\mathbb{E}\left[\tilde{Q}^{\prime}\left(\varepsilon, \varepsilon^{\prime}\right) B\left(\varepsilon^{\prime}\right)\right]=B(\varepsilon)-\tau-(1-\delta) B(\varepsilon)
$$

Period $t+1$ debt is a random variable, conditional on date $t$ information, because the price level in period $t+1$ is a function of $\varepsilon^{\prime}$.

In summary, the model I construct has a continuum of perfect foresight equilibria because the interest rate rule of the central bank is passive and because the treasury actively adjusts the tax rate to prevent the real value of debt from exploding.

\section{E. Individual Choice Problems}

A person of type $i$ solves the problem,

\section{PROBLEM 1:}

$$
\begin{gathered}
v_{i}\left[a_{i}^{s}(\varepsilon)\right]=\max _{\left\{a_{i}^{s}\left(\varepsilon^{\prime}\right)\right\}_{\varepsilon^{\prime} \in \Omega}}\left\{u_{i}\left[c_{i}^{s}(\varepsilon)\right]+\beta_{i} \pi \mathbb{E}\left[v_{i}\left(a_{i}^{s}\left(\varepsilon^{\prime}\right)\right]\right\},\right. \\
\pi \mathbb{E}\left[\tilde{Q}\left(\varepsilon, \varepsilon^{\prime}\right) a_{i}^{s}\left(\varepsilon^{\prime}\right)\right]+c_{i}^{s}(\varepsilon) \leq \mu_{i}[1-\mathcal{T}(\varepsilon)]+a_{i}^{s}(\varepsilon), \\
a_{i}^{s}\left(\varepsilon_{s}\right)=0 .
\end{gathered}
$$

Here, the symbol $v_{i}$ is the value function, $\mathcal{T}(\varepsilon) \equiv \tau+(1-\delta) B(\varepsilon)$ is a tax on the endowment and $u_{i}$, given by the expression,

$$
u_{i}(x)=\left\{\begin{array}{ccc}
\frac{x^{1-\rho_{i}}}{1-\rho_{i}} & \text { if } & \rho_{i}>0, \rho_{i} \neq 1, \\
\log (x) & \text { if } & \rho_{i}=1,
\end{array}\right.
$$

is a Von-Neumann Morgenstern utility function.

The symbol $a_{i}^{s}(\varepsilon)$ is the value of financial assets, held as Arrow securities, by a person of type $i$ born at date $s$ at the beginning of period $t$. In addition to his financial assets, this person receives an after-tax income of $\mu_{i}[1-\mathcal{T}(\varepsilon)]$ and he may borrow against future after-tax income which has a net-present value of $\mu_{i} H(\varepsilon)$.

During the period, each person may allocate his wealth to consumption, $c_{i}^{s}(\varepsilon)$, or to the accumulation of a portfolio of Arrow securities, $a_{i}^{s}\left(\varepsilon^{\prime}\right), \varepsilon^{\prime} \in \Omega$, where security $\varepsilon^{\prime} \operatorname{costs} \pi Q\left(\varepsilon, \varepsilon^{\prime}\right)$.

I show in Appendix (A) that, when people solve this problem, their consumptions in consecutive states satisfy the Euler equation,

$$
\tilde{Q}\left(\varepsilon, \varepsilon^{\prime}\right)=\beta_{i}\left(\frac{c_{i}^{s}(\varepsilon)}{c_{i}^{s}\left(\varepsilon^{\prime}\right)}\right)^{\rho_{i}},
$$


and optimal consumption is a linear function of wealth,

$$
X_{i}(\varepsilon) c_{i}^{s}(\varepsilon)=a_{i}^{s}(\varepsilon)+\mu_{i} H(\varepsilon)
$$

where, $H(\varepsilon)$ is the after-tax price of a tree, $a_{i}^{s}(\varepsilon)$ is financial wealth and $X_{i}(\varepsilon)$ is the inverse propensity to save. $X_{i}(\varepsilon)$ is defined by the recursion,

$$
X_{i}(\varepsilon)=1+\pi \beta_{i}^{\frac{1}{\rho_{i}}} \mathbb{E}\left[\tilde{Q}\left(\varepsilon, \varepsilon^{\prime}\right)^{\frac{\rho_{i}-1}{\rho_{i}}} X_{i}\left(\varepsilon^{\prime}\right)\right] .
$$

The absence of arbitrage opportunities implies the after-tax price of a tree is related to the pricing kernel and the future price of a tree by the valuation equation,

$$
H(\varepsilon)=1-[\tau+(1-\delta) B(\varepsilon)]+\pi \mathbb{E}\left[\tilde{Q}\left(\varepsilon, \varepsilon^{\prime}\right) H\left(\varepsilon^{\prime}\right)\right],
$$

where $\mathcal{T}(\varepsilon) \equiv[\tau+(1-\delta) B(\varepsilon)]$, is the real value of the primary government budget surplus. Since GDP is identically 1 , the primary budget surplus is also equal to the tax rate. It is computed by dividing Equation (1) by $p(\varepsilon)$.

\section{Rational Expectations Equilibrium}

In this section I define a rational expectations equilibrium and I show that it can be characterized by seven stochastic difference equations in seven aggregate variables.

\section{A. Definition of Equilibrium}

A government policy is a triple $\left\{Q^{N}, \tau, \delta\right\}$. A rational expectations equilibrium is a government policy, a stochastic process for $\{p, Q\}$, and a consumption allocation for each person at each date such that; 1) people of all generations and at all dates choose consumption and assets to solve Problem (1): 2) The sum of financial assets over all people alive at every date $t$ equals government debt: 3 ) The consumption of all people alive at every date $t$ is equal to the social endowment: 4) The real value of government debt follows a stationary stochastic process: and

5) The value of debt is less than the value of after-tax human wealth at every date.

An equilibrium is a complicated object that involves a wealth distribution across types and cohorts that evolves through time. Because preferences are homogeneous and because life-expectancy is independent of age, the evolution of aggregate variables is independent of this distribution. In the remainder of the paper, I exploit this independence to describe the properties of aggregate variables in equilibrium. I generate artificial data, driven by belief shocks, and I show these data mimic the properties of the post-war US data. 


\section{B. Definition of Aggregate Variables}

I will characterize the behavior of the variables $C_{i}(\varepsilon), A_{i}(\varepsilon), X_{i}(\varepsilon), B(\varepsilon), H(\varepsilon)$ and $Q\left(\varepsilon, \varepsilon^{\prime}\right) . C_{i}(\varepsilon)$ is the consumption of all type $i$ people at date $t$ in state $\varepsilon$. $A_{i}(\varepsilon)$ is the sum of the value of the $\varepsilon$ Arrow securities owned by all type $i$ people at the beginning of period $t . X_{i}(\varepsilon)$ is the inverse propensity to save out of wealth of type $i$ people. $B(\varepsilon)$ is the real value of government debt. $H(\varepsilon)$ is the after-tax price of a tree and $Q\left(\varepsilon, \varepsilon^{\prime}\right)$ is the price of an Arrow security at date $t$ in state $\varepsilon$ for delivery of an apple at date $t+1$ in state $\varepsilon^{\prime}$.

Consumptions of types 1 and 2 are linked by the goods market clearing equation

$$
C_{1}(\varepsilon)+C_{2}(\varepsilon)=1
$$

and the Arrow security holdings of types 1 and 2 are related to the outstanding value of government debt by the asset market clearing equation,

$$
A_{1}(\varepsilon)+A_{2}(\varepsilon)=B(\varepsilon) .
$$

In my description of equilibrium I define

$$
C(\varepsilon) \equiv C_{1}(\varepsilon), \quad \text { and } \quad A(\varepsilon) \equiv A_{1}(\varepsilon),
$$

and I do not explicitly model $C_{2}(\varepsilon)$ or $A_{2}(\varepsilon)$. These variables are implicitly defined by goods and asset market clearing.

\section{Seven Equations that Characterize Equilibrium}

Using the facts that consumption is linear in wealth and that the newborn cohort does not own financial assets, one may derive the following expression which connects the aggregate consumptions and financial assets of each type in consecutive states, ${ }^{5}$

$$
\tilde{Q}\left(\varepsilon, \varepsilon^{\prime}\right)=\left(\frac{C_{i}(\varepsilon) \pi \beta_{i}^{\frac{1}{\rho}_{i}}}{\pi C_{i}\left(\varepsilon^{\prime}\right)+(1-\pi) X_{i}(\varepsilon)^{-1} A_{i}\left(\varepsilon^{\prime}\right)}\right)^{\rho_{i}} .
$$

I call this the modified Euler equation.

Using the goods and asset market clearing equations, and the definitions, of $C(\varepsilon)$ and $A(\varepsilon)$, the modified Euler equations for each type are given by equations

$$
\tilde{Q}\left(\varepsilon, \varepsilon^{\prime}\right)=\left(\frac{C(\varepsilon) \pi \beta_{1}^{\frac{1}{\rho_{1}}}}{\pi C\left(\varepsilon^{\prime}\right)+(1-\pi) X_{1}(\varepsilon)^{-1} A\left(\varepsilon^{\prime}\right)}\right)^{\rho_{1}}
$$

\footnotetext{
(2011).

${ }^{5}$ For the derivation of this result, see Appendix (B), which draws on the results of Farmer et al.
} 
and

$$
\tilde{Q}\left(\varepsilon, \varepsilon^{\prime}\right)=\left(\frac{[1-C(\varepsilon)] \pi \beta_{2}^{\frac{1}{\rho}}}{\pi\left[1-C\left(\varepsilon^{\prime}\right)\right]+(1-\pi) X_{2}(\varepsilon)^{-1}\left[B\left(\varepsilon^{\prime}\right)-A\left(\varepsilon^{\prime}\right)\right]}\right)^{\rho_{2}} .
$$

In addition to equations (5) and (6), we may add up the policy function, Equation (3), over all type 1 people to give,

$$
X_{1}(\varepsilon) C(\varepsilon)=A(\varepsilon)+\mu_{1} H(\varepsilon)
$$

We also know, from the no-arbitrage pricing of assets, that the price of a tree is related to its own future price, and to the stochastic discount factor, $\tilde{Q}\left(\varepsilon, \varepsilon^{\prime}\right)$, by the equation,

$$
H(\varepsilon)=1-[\tau+(1-\delta) B(\varepsilon)]+\pi \mathbb{E}\left[\tilde{Q}\left(\varepsilon, \varepsilon^{\prime}\right) H\left(\varepsilon^{\prime}\right)\right],
$$

and government debt is related to its own future values by the budget equation,

$$
B(\varepsilon)=[\tau+(1-\delta) B(\varepsilon)]+\mathbb{E}\left[\tilde{Q}\left(\varepsilon, \varepsilon^{\prime}\right) B\left(\varepsilon^{\prime}\right)\right] .
$$

To complete the dynamic equations of the model, the inverse savings propensities are described by the equations,

$$
X_{1}(\varepsilon)=1+\pi \beta_{1}^{\frac{1}{\rho_{1}}} \mathbb{E}\left[\tilde{Q}\left(\varepsilon, \varepsilon^{\prime}\right)^{\frac{\rho_{1}-1}{\rho_{1}}} X_{1}\left(\varepsilon^{\prime}\right)\right]
$$

and

$$
X_{2}(\varepsilon)=1+\pi \beta_{2}^{\frac{1}{\rho_{2}}} \mathbb{E}\left[\tilde{Q}\left(\varepsilon, \varepsilon^{\prime}\right)^{\frac{\rho_{2}-1}{\rho_{2}}} X_{2}\left(\varepsilon^{\prime}\right)\right]
$$

Equations (5), (6), (7), (8), (9), (10) and (11) constitute a system of seven equations in the seven unknown variables $C, A, B, H, X_{1}, X_{2}$ and $Q^{\prime}$. These equations are also associated with three boundary conditions that I turn to next.

\section{Boundary Conditions, Indeterminacy and Belief Shocks as Fundamentals}

The model has three boundary conditions. One of these is a terminal condition; the other two are initial conditions.

The terminal condition asserts that the variables $H$ and $B$ must remain bounded. This rules out paths that remain consistent with equations $(5)-(11)$ for a finite number of periods but that eventually become unbounded. An unbounded path for $H$ is inconsistent with market clearing because it leads to an infinite demand 
for commodities and an unbounded path for $B$ would mean that either the government or the private sector has become insolvent. Neither variable can become unbounded in equilibrium.

The first of the two initial conditions is given by the expression,

$$
A_{1}=\bar{a}
$$

where $\bar{a}$ is the net financial assets owned by type 1 people in the first period of the model. This initial value may be positive or negative.

The second initial condition is given by the equation,

$$
B_{1}=\frac{B_{1}^{N}}{p_{1}} .
$$

This equation asserts that the initial value of government debt, measured in units of apples, depends on the period 1 price level. In models where the central bank sets an interest rate peg, there is an open set of possible values for $p_{1}$, all of which are consistent with the existence of a non-stationary perfect foresight equilibrium and all of which converge to the same steady state (Sargent and Wallace, 1975).

How should we deal with the existence of multiple equilibria? I believe it is a mistake to think of the price level as an initial condition. A better way to think of price level determination is that the price in period $t+1$, call this $p^{\prime}$, is different from the date $t$ belief of what $p^{\prime}$ will be; call this $p^{E^{\prime}}$. The date $t$ price, $p$, is connected to the belief about the date $t+1$ price, $p^{E^{\prime}}$, by the Fisher equation,

$$
p=\frac{p^{E^{\prime}} \bar{Q}^{N}}{Q^{\prime}}
$$

This way of formulating the 'problem' of multiple equilibria identifies clearly why the economist is unable to make a clear prediction: He has failed to explain how beliefs are determined. In a model with multiple equilibria, it is not enough to assert that people have perfect foresight. The economist must write down an equation to determine beliefs. The perfect foresight assumption is a consistency requirement which asserts that beliefs should be correct in the steady state of a perfect foresight model. It is not a substitute for a formal description of how beliefs are formed.

This argument can be extended to a world where there are shocks, either to preferences and endowments, or simply to beliefs. In a model where there are multiple perfect foresight equilibria, there is no reason for people to hold point expectations. In this paper I assume instead that $p^{E^{\prime}}$ is a random variable and people trading in the financial markets have common knowledge of its distribution.

The real value of debt today in state $\varepsilon$ is $\frac{1}{p(\varepsilon)}$ and thus the real cost of buying public debt that pays one dollar in the next period is $\frac{\bar{Q}^{N}}{p(\varepsilon)}$. The real price today 
of a riskless security that pays one dollar in the next period is $\mathbb{E}\left[\frac{\tilde{Q}\left(\varepsilon, \varepsilon^{\prime}\right)}{p\left(\varepsilon^{\prime}\right)}\right]$. It follows from the absence of riskless arbitrage that the price of an apple today is determined by the equation,

$$
p(\varepsilon)=\frac{\bar{Q}^{N}}{\mathbb{E}\left[\frac{\tilde{Q}\left(\varepsilon, \varepsilon^{\prime}\right)}{p^{E}\left(\varepsilon^{\prime}\right)}\right]} .
$$

Building on the research agenda laid out in Farmer (1993), I propose to resolve the indeterminacy of equilibrium by introducing a random variable, $\varepsilon^{\prime}$, and a function $p^{E}\left(\varepsilon^{\prime}\right)$ where $\varepsilon^{\prime}$ is a random variable with probability distribution $\chi$ and support $\Omega$ and $p^{E}\left(\varepsilon^{\prime}\right)$ is the price that people believe will occur if $\varepsilon^{\prime}$ is realized. The variable $\varepsilon^{\prime}$ and the function $p^{E}\left(\varepsilon^{\prime}\right)$ are new fundamentals that have the same methodological status as preferences or endowments. ${ }^{6}$

I have not yet said anything about whether the belief that $\varepsilon^{\prime}$ will be drawn from $\chi$ will be validated in equilibrium. That requires an additional assumption and I propose to assume that the belief about the distribution of future prices has the same distribution as the realized distribution of future prices. The people in my model have rational expectations.

\section{Simplifying the Model}

In this section I simplify the model by finding two variables that summarize the behavior of the other five. I call the variables that summarize the dynamics, the state variables and I call the remaining variables, the auxiliary variables. Because of the functional dependencies among the seven variables, there is no unique way of choosing state variables.

The behavior of people at date $t$ in state $\varepsilon$ depends on two factors. The first, is their belief about future prices. This is coded into their willingness to pay more or less for a claim to the future endowment and is summarized by the value of the variable $H$. The second is the value of the Arrow securities held by type 1 people which depends on the consumption of type 1 and type 2 people in period $t-1$. The easiest way to code that behavior into the model is to introduce the period $t-1$ value of consumption, I call this $C_{L}$, as an additional state variable. It is defined by the equation,

$$
C(\varepsilon)=C_{L}^{\prime}(\varepsilon)
$$

\section{A. Three Auxiliary Functions}

To characterize equilibria I will reduce the dimension of the problem still further by finding three functions, $f_{A}, f_{Q}$ and $f_{B}$, that explain $A, Q$, and $B$ as functions

\footnotetext{
${ }^{6}$ For other work that uses the belief function to resolve indeterminacy in both a theoretical and empirical context see Farmer (2012b); Farmer and Nicolò (2018); Farmer and Platonov (2016).
} 
of $C_{L}, H, X_{1}$ and $X_{2}$. This reduces the model to system of equations with a $2 \times 1$ vector of state variables, $x$, where $x \equiv\left\{H, C_{L}\right\}$ and a $3 \times 1$ vector of auxiliary variables, $y$, where $y \equiv\left\{X_{1}, X_{2}, C\right\}$.

Using Equation (7), the function $f_{A}$ is defined as

$$
A=f_{A}\left(C, H, X_{1}\right) \equiv X_{1} C-\mu_{1} H .
$$

Replacing $A$ by $f_{A}\left(C, H, X_{1}\right)$ in Equation (5), lagged one period, gives the function, $f_{Q}:[0,1]^{2} \times \mathbb{R}_{+}^{2} \rightarrow \mathbb{R}_{+}$,

$$
\tilde{Q}=f_{Q}\left(C_{L}, C, H, X_{1}\right) \equiv\left(\frac{C_{L} \pi \beta_{1}^{\frac{1}{\rho_{1}}}}{\pi C+(1-\pi) X_{1}^{-1} f_{A}(C, H)}\right)^{\rho_{1}}
$$

Finally, the function $f_{B}:[0,1]^{2} \times \mathbb{R}_{+}^{3} \rightarrow \mathbb{R}$, is implicitly defined by the expression,

$$
\begin{aligned}
& \left(\frac{\pi \beta_{1}^{\frac{1}{\rho_{1}}} C_{L}}{\pi C+(1-\pi) X_{1}{ }^{-1} f_{A}\left(C, H, X_{1}\right)}\right)^{\rho_{1}}= \\
& \left(\frac{\pi \beta_{2}^{\frac{1}{\rho_{2}}}\left(1-C_{L}\right)}{\pi(1-C)+(1-\pi) X_{2}{ }^{-1}\left[f_{B}\left(C_{L}, C, H, X_{1}, X_{2}\right)-f_{A}\left(C, H, X_{1}\right)\right]}\right)^{\rho_{2}} .
\end{aligned}
$$

For given values of $C_{L}, C, H, X_{1}$ and $X_{2}, B \equiv f_{B}\left(C_{L}, C, H, X_{1}, X_{2}\right)$, is the real value of government debt that equates the marginal rates of substitution of types 1 and 2.

It is important to note that Equation (16) holds for all pairs of states $\left\{\varepsilon, \varepsilon^{\prime}\right\}$. The fact that $B^{\prime}$ is a function of $\varepsilon^{\prime}$ is recognized in advance by type 1 and type 2 people in period $t$ who equate their marginal rates of substitution by trading a complete set of Arrow securities.

\section{B. Solving the Model}

Let $\mathcal{S} \equiv \mathbb{R}_{+} \times[0,1]$ be the state space and let $\mathcal{Y} \equiv \mathbb{R}_{+}^{2} \times[0,1]$ be the control space. Using the functions $f_{A}, f_{Q}$, and $f_{B}$, together with equations (8)-(11), I 
define a function $\mathcal{S}^{2} \times \mathcal{Y}^{2} \rightarrow \mathbb{R}^{5}$,

$$
\begin{aligned}
& \tilde{F}\left(C_{L}, H, C, X_{1}, X_{2}, C_{L}^{\prime}, H^{\prime}, C^{\prime}, X_{1}^{\prime}, X_{2}^{\prime}\right) \\
& {\left[\begin{array}{lr}
H-1+\tau+(1-\delta) f_{B}\left(C_{L}, C, H, X_{1}, X_{2}\right)-\pi f_{Q}\left(C, C^{\prime}, H^{\prime}, X_{1}^{\prime}\right) H^{\prime} \\
f_{Q}\left(C, C^{\prime}, H^{\prime}, X_{1}^{\prime}\right) f_{B}\left(C, C^{\prime}, H^{\prime}, X_{1}^{\prime}, X_{2}^{\prime}\right)-f_{B}\left(C_{L}, C, H, X_{1}, X_{2}\right) \\
X_{1}-1-\pi \beta_{1}^{\frac{1}{\rho_{1}}} f_{Q}\left(C, C^{\prime}, H^{\prime}, X_{1}^{\prime}\right)^{\frac{\rho_{1}-1}{\rho_{1}}} X_{1}^{\prime} & +\tau+(1-\delta) f_{B}\left(C_{L}, C, H, X_{1}, X_{2}\right) \\
X_{2}-1-\pi \beta_{2}^{\frac{1}{\rho_{2}}} f_{Q}\left(C, C^{\prime}, H^{\prime}, X_{1}^{\prime}\right)^{\frac{\rho_{2}-1}{\rho_{2}}} X_{2}^{\prime} & \\
C-C_{L}^{\prime} &
\end{array}\right.}
\end{aligned}
$$

More compactly,

$$
F\left(x, y, x^{\prime}, y^{\prime}\right) \equiv \tilde{F}\left(C_{L}, H, C, X_{1}, X_{2}, C_{L}^{\prime}, H^{\prime}, C^{\prime}, X_{1}^{\prime}, X_{2}^{\prime}\right) .
$$

A rational expectations equilibrium is characterized by functions $f: \mathcal{S} \times \Omega \rightarrow \mathcal{S}$ and $g: \mathcal{S} \rightarrow \mathcal{Y}$ that satisfy the functional equation,

$$
\mathbb{E}\left\{F\left(x, g(x), f\left(x, \varepsilon^{\prime}\right), g\left[f\left(x, \varepsilon^{\prime}\right]\right)\right\}=0 .\right.
$$

I now turn to the problem of solving this functional equation numerically using a local approximation.

\section{Approximating the Rational Expectations Equilibrium with Perturbation Methods}

Define a steady state to be a state vector $\bar{x}$ and a control vector $\bar{y}$ that satisfies the equation

$$
F(\bar{x}, \bar{y}, \bar{x}, \bar{y}),
$$

and let $\bar{J}_{1}$ and $\bar{J}_{2}$ be the Jacobian matrices of $F$ with respect to $[x, y]$ and $\left[x^{\prime}, y^{\prime}\right]$ evaluated at $\{\bar{x}, \bar{y}\}$.

Local uniqueness of a solution to Equation (17) requires that two of the generalized eigenvalues of the matrix pencil $\left\{\bar{J}_{1}, \bar{J}_{2}\right\}$ are inside the unit circle. ${ }^{7}$ That condition guarantees that there is a two-dimensional stable manifold $g(x)$ with the property that for any $x_{1} \in \mathcal{N}(\bar{x})$ all initial conditions $y_{1}=g\left(x_{1}\right)$ that begin on the stable manifold, converge asymptotically to the steady state $\{\bar{x}, \bar{y}\}$.

\footnotetext{
${ }^{7}$ The matrix pencil of the matrices $\left\{\bar{J}_{1}, \bar{J}_{2}\right\}$ is the matrix valued function $\mathbb{L}(\lambda)=\bar{J}_{1}-\lambda \bar{J}_{2}$, for $\lambda \in \mathbb{C}$. The generalized eigenvalues of $\left\{\bar{J}_{1}, \bar{J}_{2}\right\}$ are solutions to the polynomial equation $\left|\bar{J}_{1}-\lambda \bar{J}_{2}\right|=0$, and the generalized eigenvectors, $v$, are solutions to the equation $\bar{J}_{1} v=\lambda \bar{J}_{2} v$, where $v$ is a vector and $\lambda$ is a scalar (Gantmacher, 2000, Chapter XII). Both $v$ and $\lambda$ may take complex values. The generalized eigenvalue problem is used to solve linearized systems where $\bar{J}_{1}$ and or $\bar{J}_{2}$, or both, are singular. It is widely applied to the solution of linear rational expectations models. See Sims (2001) for a description of the method.
} 
To a first approximation, $g$ coincides with the linear subspace spanned by the two eigenvectors associated with the two stable eigenvalues and $f$ coincides with the linearized dynamics of $x$ on the stable manifold. When $F$ is differentiable, higher order approximations may be obtained by extending the solution along the stable manifold using second, third and higher order derivatives.

To study the properties of rational expectations equilibria, in the next section I provide numerical values for the model parameters and I approximate the solution using perturbation methods around a steady-state equilibrium.

\section{The Properties of a Calibrated Model}

\section{A. Two Different Calibrations}

To study the properties of the model, I calibrated it in two different ways. In both calibrations I chose common values for $\pi, \mu_{1}, \tau$ and $\delta$. These values are reported in Table 1 . The values are not chosen systematically to match first and second moments of US data. They are designed to show that a model, with the features I have built into it, has promise as a theoretical vehicle to replicate data if one were to conduct a more serious econometric exercise.

\begin{tabular}{l|c|c}
\hline \hline Concept & Symbol & Calibrated Values \\
\hline Life expectancy & $\frac{1}{1-\pi}$ & 50 years \\
Survival probability & $\pi$ & 0.98 \\
Fraction of type 1 people & $\mu_{1}$ & 0.5 \\
Tax ( - ve value denotes Transfer) & $\tau$ & -0.01 \\
Debt Repayment Parameter & $\delta$ & 0.94 \\
Nominal Discount Factor & $\bar{Q}^{N}$ & 0.95 \\
\hline \hline
\end{tabular}

Table 1 - Common Parameter Values for Two Calibrations of the Model

In the common parameter calibrations I chose $\pi$ to be 0.98 . That value implies that an average person has an age-independent life expectancy of 50 years. I experimented with different values for $\mu_{1}$ and found that the qualitative features of the model are similar for calibrations in the range 0.25 to 0.75 . The results I report are for $\mu_{1}=0.5$.

I chose $\bar{Q}^{N}=0.95$ for the monetary policy parameter which implies the central bank targets a nominal interest rate of $5 \%$ which is in accord with US data in which the average three month treasury bill rate in the post-war period was $4.7 \%$. The only steady-state variable influenced by $\bar{Q}^{N}$, is the level of the inflation factor which is scaled up or down by changes in $\bar{Q}^{N}$. For fiscal policy, I chose a value of $\tau=-0.01$, which means that the treasury sets a state-independent real transfer of $1 \%$ of GDP and I set $\delta=0.94$, which implies that the treasury adjusts the tax 
rate each period to repay $6 \%$ of outstanding debt. ${ }^{8}$

In the calibrations that differ across simulations I chose coefficients of risk aversion of 1 and 6 . For the logarithmic calibration, $\rho_{1}=\rho_{2}=1$, I chose discount factors for type 1 people of 0.9765 and for type 2 people of 0.9465 . For the CRRA calibration I set $\rho_{1}=\rho_{2}=6$ and I chose discount factors for type 1 people of 1 and for type 2 people of 0.97 .

\begin{tabular}{l|c|c}
\hline \hline Concept & Symbol & Calibrated Values \\
\hline \hline Calibration 1 & & \\
\hline Risk Aversion of Type 1 & $\rho_{1}$ & 1 \\
Discount factor of type 1 people & $\beta_{1}$ & 0.9765 \\
Risk Aversion of Type 2 & $\rho_{2}$ & 1 \\
Discount factor of type 2 people & $\beta_{2}$ & 0.9465 \\
\hline Calibration 2 & & \\
\hline Risk Aversion of Type 1 & $\rho_{1}$ & 6 \\
Discount factor of type 1 people & $\beta_{1}$ & 1 \\
Risk Aversion of Type 2 & $\rho_{2}$ & 6 \\
Discount factor of type 2 people & $\beta_{2}$ & 0.97 \\
\hline \hline
\end{tabular}

Table 2-Parameter Values that Differ Across Calibrations

I chose these numbers by experimenting with empirical simulations to match a safe return of $3.5 \%$ in both calibrations. ${ }^{9}$ For both calibrations I maintained a difference in discount rates of $3 \%$. The gap between the discount rates of the two types determines the volume of trade between private agents and it allows me to construct a model in which a fraction of the private sector are net debtors.

\section{B. The Steady States of the Two Calibrations}

In Table 3 I report some statistics associated with my two calibrations. In the first row I report the stable generalized eigenvalues of $\left\{\bar{J}_{1}, \bar{J}_{2}\right\}$. For both calibrations there are two eigenvalues inside the unit circle and in each calibration, both roots are close to 1 . This fact accounts for the ability of the model to explain persistent movements in $\mathrm{PE}$ ratios.

In rows 2 and 3 of the table I report steady state values of the real interest rate $100\left(\frac{1}{Q}-1\right)$ and the inflation rate $100(\Pi-1)$ for the non-stochastic steady state. For the logarithmic calibration, the steady state real interest rate is $3.2 \%$

\footnotetext{
${ }^{8}$ For existence of equilibrium, it is not necessary that the tax rate be adjusted every period. It simply needs to be adjusted occasionally to prevent debt from exploding.

${ }^{9}$ This number is higher than the mean safe real return in US data, which is $1.37 \%$, but it was the lowest safe return that I could generate for the CRRA calibration without giving Type 1 people a negative discount rate. There is nothing that prevents a negative discount rate because agents discount the future not only because of a pure rate of time preference that is measured by $\beta_{1}$ and $\beta_{2}$, but also because of the probability of survival that is measured by the parameter $\pi$.
} 


\begin{tabular}{l|c|c|c}
\hline \hline Variable & Symbol & $\rho=1$ & $\rho=6$ \\
\hline Stable Generalized Eigenvalues & $\lambda_{1}, \lambda_{2}$ & $0.965,0.97$ & $0.954,0.979$ \\
\hline Real Interest Rate & $100\left(\frac{1}{\bar{Q}}-1\right)$ & $3.2 \%$ & $1.42 \%$ \\
Inflation Rate & $100(\bar{\Pi}-1)$ & $1.78 \%$ & $3.5 \%$ \\
Nominal Interest Rate & $100\left(\frac{1}{\bar{Q}^{N}}-1\right)$ & $5 \%$ & $5 \%$ \\
\hline \hline
\end{tabular}

Table 3-Steady Values of the Interest Rate for Two Different Calibrations of Risk AverSION

and the steady-state inflation rate is $1.78 \%$. For the CRRA calibration the real interest rate is $1.42 \%$ and the steady-state inflation rate is $3.5 \%$. In both cases, the inflation rate is found by subtracting the real rate from the targeted nominal interest rate which $I$ set at $5 \%$.

It is important to stress that the real interest rate in the non-stochastic steady state is not the same as the median real return in stochastic simulations of the model where higher order terms can generate a sizable risk premium. I will show in Section V.D that, for a model that replicates the volatility of asset prices in the data, the median safe return for both calibrations is approximately $3.5 \%$. For the CRRA calibration the median return on a risky asset is $5.4 \%$ and for the logarithmic calibration it is $3.17 \%$.

\section{Two Stochastic Simulations Using the Same Draw for the Shocks}

I simulated 90 years of data for the inflation rate, the stochastic discount factor, the real safe rate of return and the real risky rate of return and I discarded the first 30 observations to remove the influence of initial conditions. The results of this simulation are reported in Figure 1. On all four panels, the solid curves represent a simulation for logarithmic preferences and the dashed curves represent a simulation for CRRA preferences with $\rho=6$. For both simulations I used the same sequence of stochastic shocks.

I simulated data using the function

$$
x^{\prime}=\hat{f}(x)+\eta \varepsilon^{\prime},
$$

where $\hat{f}$ is a second order approximation to the policy function computed using the code from Levintal (2017) and $\eta$ is a $2 \times 1$ vector that allocates shocks to state variables. ${ }^{10}$ To ensure that $H$ does not become negative, I defined the state variable to be $\log (H)$ rather than $H$.

I chose the vector $\eta=[\sigma, 0]^{T}$ and I used a normal distribution for $\varepsilon^{\prime}$ with

\footnotetext{
${ }^{10}$ Levintal's code is based on Schmitt-Grohé and Uribe (2004). It allows for approximations up to fifth order and it is faster and more efficient than the Schmitt-Grohé-Uribe code. I found no noticeable difference in simulations using second and higher order approximations and, because the second-order approximation is faster, I used it in my simulations.
} 
a standard deviation of $\sigma=0.15$. A zero appears in the second element of $\eta$ to reflect the fact that $C_{L}$ is predetermined. The parameter $\sigma$ is the standard deviation of a belief shock that causes people to revise their view of the current price of a tree. The implied belief about the price shock, $p(\varepsilon)$, can be recovered from the definition

$$
p(\varepsilon)=\frac{B^{N}}{B} .
$$

I chose a standard deviation of 0.15 for the belief shock to make the Sharpe ratio as large as possible and to simultaneously to get as close as possible to the realized volatility of stock market returns. I show in Section V.D, that this calibration leads to a standard deviation of the risky rate of 17 in the CRRA calibration which compares with 14 in data.

The top left panel of Figure 1 reports the inflation rate, measured in percent per year, and the top right panel is the stochastic discount factor which is a pure number. These series are identical up to a scale normalization, because, when the central bank pegs the nominal interest rate, fluctuations in the realized stochastic discount factor are caused by fluctuations in the realized inflation rate.

The bottom left panel of Figure 1 is the safe interest rate, defined by the expression

$$
r^{s}=100\left(\frac{1}{\mathbb{E}\left[\tilde{Q}\left(\varepsilon, \varepsilon^{\prime}\right)\right]}-1\right) .
$$

I computed this statistic by adding an addition auxiliary variable, $R^{s} \equiv 1+r^{s}$, and an additional auxiliary equation

$$
\frac{1}{R^{s}}-\mathbb{E}\left[f_{Q}\left(C, C^{\prime}, H^{\prime}, X_{1}^{\prime}\right)\right]=0
$$

to the model.

The bottom right panel is the realized after-tax one-period holding return for buying a measure 1 of trees in period $t$ and selling it in period $t+1$. It is defined by the expression

$$
r^{r}=100\left(\frac{\pi H\left(\varepsilon^{\prime}\right)}{H(\varepsilon)-[1-\mathcal{T}(\varepsilon)]}-1\right) .
$$

The safe return, $r^{s}$, and the risky return, $r^{r}$, are identical in a non-stochastic steady state. They are very different in the stochastic steady state.

In US data, the average yield from holding the stock market is approximately $6 \%$ higher than the average return from holding government bonds. Because it is possible to increase the risky return by assuming more risk, it is common to report the Sharpe ratio which is a measure of excess return normalized by risk. The Sharpe ratio, $S$, is defined as,

$$
S \equiv \frac{\operatorname{mean}\left(r^{r}-r^{s}\right)}{\operatorname{std}\left(r^{r}\right)} .
$$



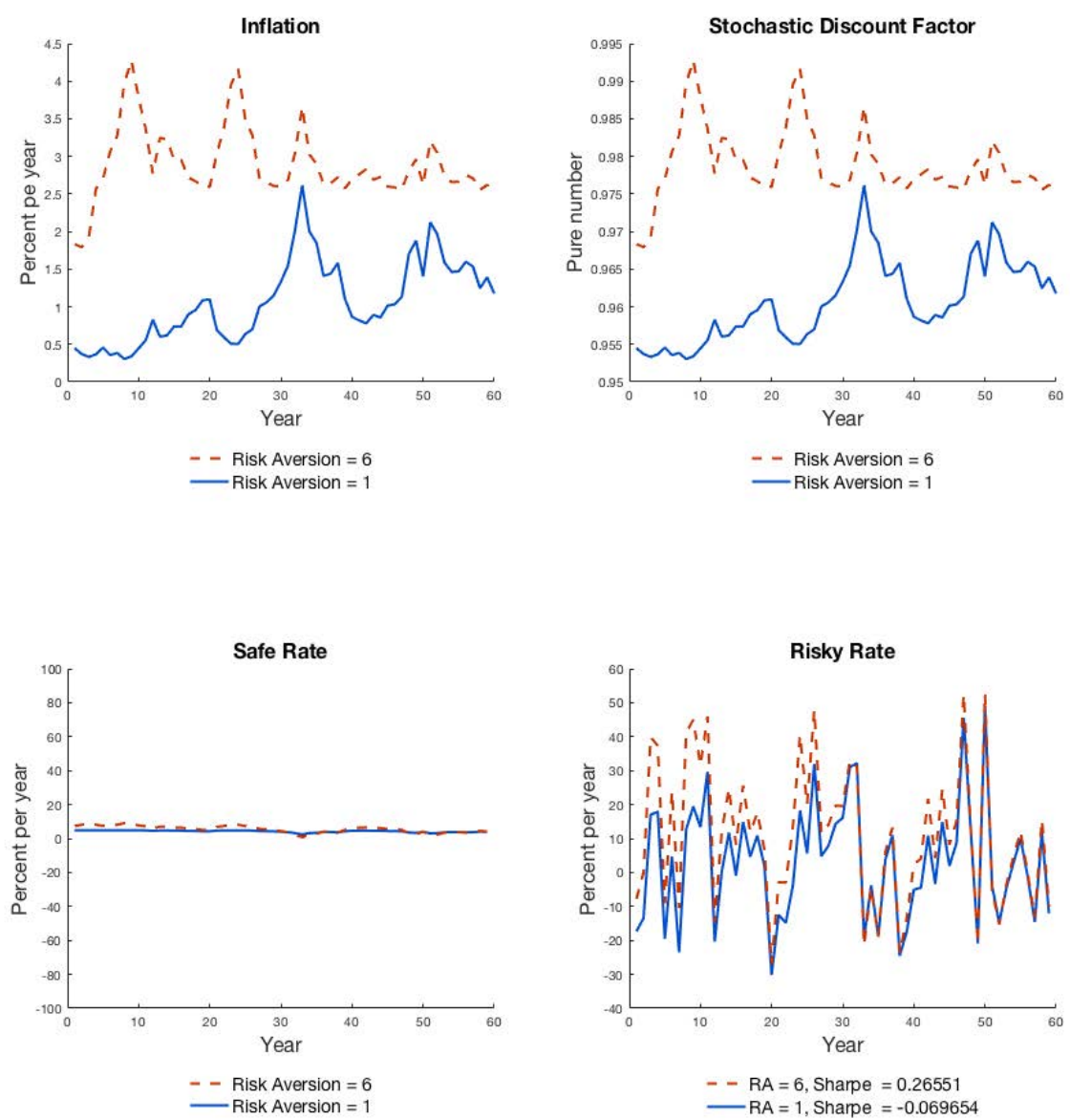

Figure 1. Inflation and Interest Rates for Two Different Calibrations

In US data, the Sharpe ratio is somewhere between 0.25 and 0.5 and it is sensitive to the definition of the risky asset and the time period over which the statistic is computed (Cochrane, 2001). In Table 4 I report the Sharpe ratio and the means of the safe and risky returns for the simulations from Figure 1.

The numbers reported in this table refer to a single draw of shocks. When people have logarithmic preferences, this draw led to an average safe interest rate in 60 years of data of $4.23 \%$ and an average risky rate of $3.03 \%$. The Sharpe ratio for this draw, for the case of logarithmic preferences, is -0.069 .

When people have CRRA preferences, with risk aversion parameter $\rho=6$, this 


\begin{tabular}{l|c|c|c}
\hline \hline Variable & Symbol & $\rho=1$ & $\rho=6$ \\
\hline Mean of Safe Rate in One Simulation & $\bar{r}^{s}$ & $4.23 \%$ & $5.51 \%$ \\
Mean of Risky Rate in One Simulation & $\bar{r}^{r}$ & $3.03 \%$ & $10.96 \%$ \\
Sharpe Ratio in One Simulation & $S$ & -0.069 & 0.26 \\
\hline \hline
\end{tabular}

Table 4-Mean Safe and Risky Rates for a Single Simulation

same sequence of stochastic shocks led to a mean safe return of $5.51 \%$ and a mean risky return of $10.96 \%$. The equity premium for this calibration is $5.45 \%$ and the Sharpe ratio is 0.26 . The mean returns are different from the steady-state values reported in Table 1, because the model has an eigenvalue close to 1 and mean reversion is extremely slow. The average risky return in 60 years of data is a random variable with a high variance that becomes very large as the largest root of the system approaches 1 .

\section{The Distributions of Average Returns in 100,000 Simulations}

To check whether a relatively high Sharpe ratio was a freak draw from a particular realization of the shocks, I simulated 100,000 time series, each of length 60 years, and for each series I computed the Sharpe ratio and the means of the safe and risky interest rates. The results are reported in Figure 2 for two different calibrations of the model and the medians, fifth and ninety-fifth percentiles for these simulations are reported in Table $5 .{ }^{11}$ For both calibrations, I used the same sequence of random shocks for every simulation.

The top left panel of Figure 2 compares the densities of the average safe returns. This panel shows that the distribution of safe rates has a higher variance in the CRRA case. However, the median safe return is $3.6 \%$ in the logarithmic case and $3.5 \%$ for CRRA preferences with a coefficient of risk aversion of 6 . This similarity is deliberate and is one of the moments I targeted in my calibrations by adjusting the discount factors of the people in the two cases.

The top right panel of Figure 2 plots the empirical distribution of 60-year averages of risky rates. The economy with higher risk aversion leads to a distribution of risky rates that is shifted right with a higher median of $5.44 \%$ for the CRRA calibration as opposed to $3.17 \%$ for the logarithmic calibration. The CRRA calibration also has a longer right tail with a 95 'th percentile of $13.43 \%$ compared to $5.83 \%$ for the logarithmic economy.

The middle left panel of Figure 2 plots the densities of Sharpe ratios for the two calibrations in 100,000 replications and the middle right panel shows the densities

\footnotetext{
${ }^{11}$ For the column headed "US data", the raw data for inflation and the safe interest rate are from the Bureau of Economic Analysis. Data for the risky rate and the PE ratio are from Shiller (2014). All statistics are averages of annual series from 1948 through 2008. Inflation is the average twelve month percentage increase in the CPI. The safe rate is the three month treasury bill rate minus realized inflation. The risky rate and its standard deviation are computed from the one year holding return on the S\&P 500 adjusted for CPI inflation. The PE ratio is Robert Shiller's Cyclically Adjusted Price Earnings Ratio.
} 


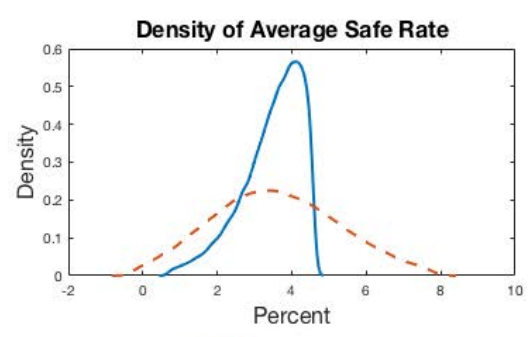

- - Risk Aversion $=6$ - Risk Aversion $=1$

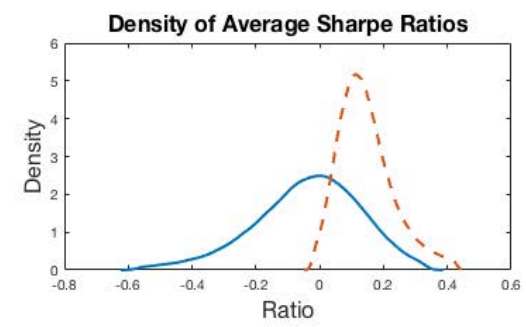

- - Risk Aversion $=6$ Risk Aversion $=1$

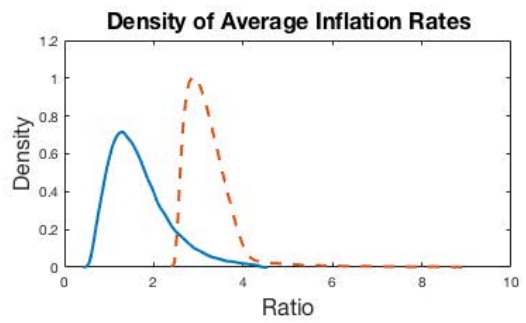

- - Risk Aversion $=6$ Risk Aversion $=1$

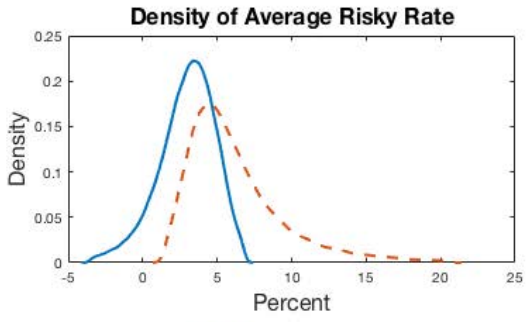

- - Risk Aversion $=6$ Risk Aversion $=1$

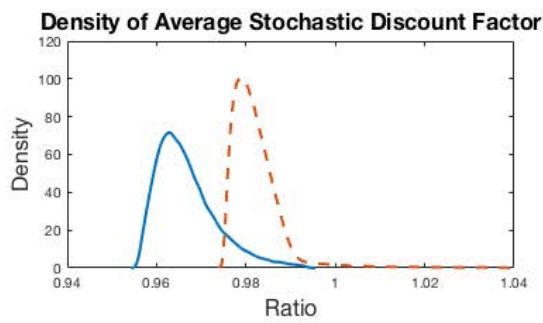

- - Risk Aversion $=6$ Risk Aversion $=1$

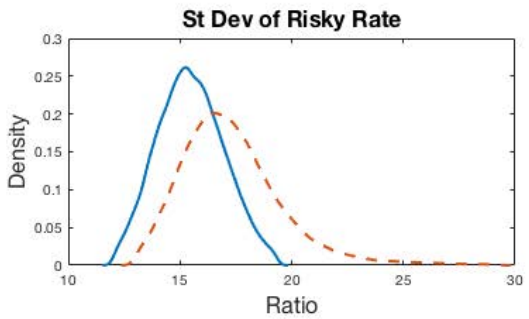
- Risk Aversion $=6$
- Risk Aversion $=1$

Figure 2. Empirical Frequency of Interest Rates and Sharpe Ratios in 100,000 Simulations

of the average stochastic discount factors. It is clear from the left panel that in the logarithmic calibration the distribution of Sharpe ratios is approximately symmetric and centered around zero. In contrast, for the CRRA calibration almost all of the probability mass is greater than zero and there is a significant 


\begin{tabular}{l|c|c|c|c}
\hline \hline Concept & 5'th percentile & Median & 95’th percentile & US data \\
\hline \hline Log. calibration $\rho=1$ & & & & \\
\hline Safe rate & $1.77 \%$ & $3.63 \%$ & $4.49 \%$ & $1.14 \%$ \\
Risky rate & $-0.78 \%$ & $3.17 \%$ & $5.83 \%$ & $7.74 \%$ \\
Sharpe ratio & -0.36 & -0.024 & 0.23 & 0.46 \\
Stochastic discount factor & 0.96 & 0.97 & 0.98 & $\mathrm{NA}$ \\
Inflation & $0.8 \%$ & $1.53 \%$ & $5.83 \%$ & $3.7 \%$ \\
St. dev. of risky rate & 12.9 & 15.4 & 18.1 & 14.4 \\
PE ratio & 7.45 & 15.45 & 30.89 & 18.33 \\
Nominal interest rate 5\% & $5 \%$ & $5 \%$ & $5 \%$ & $4.7 \%$ \\
\hline CRRA calibration $\rho=6$ & & & & \\
\hline Safe rate & $0.73 \%$ & $3.51 \%$ & $6.60 \%$ & $1.14 \%$ \\
Risky rate & $2.37 \%$ & $5.44 \%$ & $13.43 \%$ & $7.74 \%$ \\
Sharpe ratio & 0.02 & 0.14 & 0.33 & 0.46 \\
Stochastic discount factor & 0.97 & 0.98 & 0.99 & $\mathrm{NA}$ \\
Inflation & $2.62 \%$ & $3.11 \%$ & $13.43 \%$ & $3.7 \%$ \\
St. dev. of risky rate & 14.1 & 17.0 & 21.8 & 14.4 \\
PE ratio & 9.88 & 17.91 & 28.30 & 18.33 \\
Nominal interest rate 5\% & $5 \%$ & $5 \%$ & $5 \%$ & $4.7 \%$ \\
\hline \hline
\end{tabular}

TABle 5-Percentiles OF 60-YeAR AVERAGES IN 100, 000 Simulations

probability of observing a Sharpe ratio of 0.3 or higher.

Turning to the middle right panel of Figure 2, we see that the distribution of the stochastic discount factor is shifted to the right for the CRRA calibration relative to the case of logarithmic preferences. This reflects the fact that the time preference rates of the two types were chosen to be 1 and 0.97 when risk aversion is 6 and 0.9765 and 0.9465 for the logarithmic case. The lower left panel of Figure 2 reports the densities of average 60-year inflation rates and the lower right panel plots the distribution of the 60-year average standard deviations of risky rates.

With the exception of the safe interest rate and the Sharpe ratio, the CRRA calibration does a reasonable job of matching the US data and I infer, from these simulations, that this model is a good candidate for helping understand the equity premium puzzle (Mehra and Prescott, 1985).

\section{E. Consumption, Asset Holdings and Government Debt}

In Table 6 I report the distribution of simulated quantity data for my 100, 000 simulations and I compare these statistics with some back of the envelope estimates of US data. Debt to GDP ratios for both the private sector and the public sector have been growing over the past couple of decades and averaging these data over time will not lead to a sensible estimate of sustainable long-run aver- 
ages. The numbers reported under the heading US Data are representative of the kinds of numbers that have characterized US data in the post-war period. The reported figure of $-3 \%$ for the US primary surplus hides a couple of significant fiscal reforms that we capture in the model as a time-invariant fraction of debt to be paid back every year.

The reported figure of Type 1 assets of $150 \%$ of US GDP reflects the fact that over the past decade, government debt has averaged $80 \%$ of GDP and private debt has averaged $70 \%$. Adding these figures together, there is implicitly, a group of private wealth holders who are lending both to the government and to private borrowers and I report their wealth in US data as 150\% of US GDP under the heading of 'Type 1 Assets'. These estimates ignore the existence of public and private capital which are not a part of my stylized model. ${ }^{12}$

\begin{tabular}{l|c|c|c|c}
\hline \hline Concept & 5'th percentile & Median & 95'th percentile & US Data \\
\hline \hline Log. calibration $\rho=1$ & \multicolumn{4}{|c}{ Percentage of GDP } \\
\hline Type 1 consumption & 58 & 70 & 80 & NA \\
Type 1 assets & -175 & 859 & 1,481 & 150 \\
Government debt & $-1,216$ & 505 & 1,455 & 70 \\
Primary budget surplus & -74 & 29 & 86 & -3 \\
\hline \hline CRRA calibration $\rho=6$ & \multicolumn{4}{|c}{ Percentage of GDP } \\
Type 1 consumption & 53 & 54 & 55 & NA \\
Type 1 assets & 61 & 145 & 174 & 150 \\
Government debt & -83 & 67 & 127 & 70 \\
Primary budget surplus & -6.1 & 3.1 & 6.7 & -3 \\
\hline \hline
\end{tabular}

Table 6-Percentiles of 60-year averages in 100, 000 Simulations

The consumption of type 1 people fluctuates between $58 \%$ and $80 \%$ of GDP for the logarithmic calibration and their asset holdings fluctuate between $-175 \%$ and 1,481\% of GDP. These massive asset fluctuations are reflected in even larger swings in government debt which at the fifth percentile, is equal to $-1,216 \%$ of GDP and at the ninety-fifth percentile, is equal to 1,455\% of GDP. Recall that these are 60-year averages of simulated data and they are very far from anything we have observed in data. They imply, for example, that there is a five percent chance that we would observe a sixty-year run of data in which the US government owns assets equal to 1,216 times GDP and a further five percent chance that we would see the government holding debt equal to 1, 455 times GDP. Further, this calibration implies we could expect to see a primary budget surplus that fluctuates between $-74 \%$ and $+86 \%$ of GDP. The median value of government debt, for this

\footnotetext{
${ }^{12}$ Although some of these wealth holders may reside outside of the US, the US has fluctuated over the past few decades between being a net foreign creditor and a net foreign debtor so the assumption that all wealth is held domestically may not be too misleading.
} 
calibration, is $505 \%$ of GDP.

The CRRA calibration is em much more promising as a description of data. Here, the consumption of type 1 people fluctuates between $53 \%$ and $55 \%$ of GDP and their asset holdings fluctuate between $61 \%$ and $174 \%$ of GDP. Accompanying these swings in private asset holdings of patient people, government debt swings between $-83 \%$ of GDP at the fifth percentile and $127 \%$ at the ninety-fifth percentile. The median value of government debt is $67 \%$ which is not far from US experience in which government debt has fluctuated between $30 \%$ and $120 \%$ of GDP in the post-WWII period. The primary surpluses we would expect to see in this calibration fluctuate between plus and minus $6 \%$ of GDP which are also not unreasonable relative to recent experience.

\section{F. A Discussion of the Results}

In the introduction, I claimed that the paper relies on three features. First, there must be birth and death. Second, there must be nominally denominated government debt and third there must be two types of people. Here, I discuss why each of these features is important and I speculate on the ability of a model in this class to provide a vehicle for more formal empirical work.

Consider first, the assumption of perpetual youth consumers which is a simple way of capturing features of the overlapping generations model while preserving the ability to fit annual time-series data. If we set the parameter $\pi$ to 1 , the model collapses to an economy with two infinitely lived representative agents with different discount factors. The more patient of the two agents will eventually own all of the wealth and, asymptotically, the model behaves like a one person representative agent economy in which equilibrium is unique. Assuming a single type of agent does not help since, in this case, the model starts out as a representative agent model and, once again, equilibrium is unique. It follows that we need the perpetual youth assumption to generate asset price fluctuations caused by belief shocks. ${ }^{13}$

Suppose we were to construct a perpetual youth model with no nominal asset. This model would have a unique locally determinate equilibrium and it would therefore be unable to generate equilibria driven by belief shocks. Introducing fiat money does not help. The perpetual youth model with fiat money, like the two-period overlapping generations model, has a steady state equilibrium where money has value but this steady state is determinate and there is a unique initial price level for every initial distribution of nominal assets. To generate the results of the paper it is critical that we interpret the nominal asset as government debt and, importantly, the government must follow a passive fiscal policy in which it balances its intertemporal budget for all possible price paths.

The assumptions of perpetual youth and passive monetary and fiscal polices are essential to the mechanism of my model. They allow me to construct a locally

\footnotetext{
${ }^{13}$ See Kehoe and Levine (1985) for a discussion of the properties of the infinite horizon model in which agents live for ever and have different discount rates.
} 
indeterminate steady-state equilibrium where money has value. In contrast to these two assumptions, the role of two types of people is less important. In the model with only one type of person there will still be asset price fluctuations but there will be no asset market trade between types. By adding patient and impatient people, I am able to construct an equilibrium in which there is active trade in Arrow securities and where a price shock sets off a persistent mean reverting movement in asset portfolios.

But although the assumption of two types of people is not essential to the mechanism of the model, it is important to the quantitative calibration. In the past decade, private debt in the United States was approximately $80 \%$ of GDP which accords well with the calibration in Table 6 for the case of CRRA preferences. I am matching this statistic by assuming that debt is accumulated by Type 2 people and that Type 1 people lend $70 \%$ of GDP to the government and $80 \%$ to Type 2 people. If the model had only one type, it would be impossible to match this figure for private debt accumulation and government debt would need to be more volatile over the business cycle to match the asset price data.

It is well known that dynamic monetary models with an interest-rate peg lead to indeterminacy of equilibrium but most existing work in monetary economics has argued that this case is not empirically relevant. Alas, that is not the case. Jordi Galí and Mark Gertler (2000) have shown that, in the period before 1979, the US Federal Reserve operated a passive monetary policy that is predicted, in New Keynesian models, to lead to indeterminacy of the price level. ${ }^{14}$

One solution to the 'problem' of multiple equilibria in models with passive monetary policy is to appeal to the fiscal theory of the price level (FTPL). This theory claims that government debt will remain bounded even in the case when the government makes no active attempt to remain solvent and it is used to select a unique equilibrium in monetary models in which the price level is otherwise indeterminate.

I find the arguments that have been presented for the FTPL to be unpersuasive. If the FTPL held in practice, I do not believe that legislatures would be as concerned with budget balance as they have proven to be in the real world. In my view, we should deal with the existence of multiple equilibria by modelling the way people form beliefs. We must introduce a belief function as a new fundamental as I first argued in Farmer (1993) and as I have done in this paper.

One might argue that, although monetary policy has been passive for significant periods of US history, it has not always been passive. In the period from 1983 to 2008 estimates of monetary policy rules suggest that central banks responded aggressively to inflation by raising interest rates more than one-for-one in response to inflation. If an active rule like that were inserted into the model of this paper, it would lead to explosive behavior of inflation and asset prices if people continued

\footnotetext{
${ }^{14} \mathrm{~A}$ passive monetary policy is an interest rate rule in which the central bank responds to inflation by raising or lowering the interest rate by less than one-for-one (Leeper, 1991). An active monetary policy is one where it responds to inflation by raising or lowering the interest rate by more than one-for-one.
} 
to use the belief function that I used to resolve indeterminacy of equilibrium.

I am not concerned with this critique of my approach because I do not believe the New Keynesian model is the right lens through which to interpret these data. In a recent theoretical paper, Konstantin Platonov and I (Farmer and Platonov, 2016) introduce an alternative theory of the connection between output and inflation in which the belief function determines equilibrium even if monetary policy is active. Giovanni Nicolò and I (Farmer and Nicolò, 2018) have shown that this theory outperforms the New-Keynesian model in post-WWII US data.

The papers with Platonov and Nicoló build on Farmer (2012a) which constructs a theory where the steady-state of the model is indeterminate as a consequence of incomplete labor markets. What I have shown in the current paper is that models with indeterminacy can explain asset pricing data. I remain eclectic as to exactly how to model indeterminacy in practice and I suspect that a combination of incomplete participation that characterizes overlapping generations models and incomplete labor markets that characterizes my work on unemployment will both be needed to understand US data.

There is one other feature of my explanation for the equity premium that is worth drawing attention to. The model generates a smooth risk-free rate even when the risky rate is very volatile. This is in marked contrast to explanations of the risk premium such as Abel et al. (1989) or Campbell and Cochrane (1999) that are based on habit-formation preferences. ${ }^{15}$

In my model, the generations who participate in the asset markets are willing and able to reallocate assets intertemporally. To a first approximation, the safe rate is equal to the slope of an indifference curve of a person with CRRA preferences and big swings in the safe rate would cause these people to reallocate consumption through time. It is the ability of these people to trade with each other that prevents excessive volatility of the safe rate of return.

Why then is the risky rate so volatile? Although I assume that there is a complete set of Arrow securities, the unborn generations are unable to participate in the asset markets that open before they are born. The inability of the unborn to insure opens the possibility that self-fulling belief shocks will generate substantial movements in the after-tax wealth of the unborn that are reflected in big swings in the stochastic discount factor. These swings cause long-dated assets to undergo substantial revaluations that result in large gains or losses on long-dated assets.

I conclude that models with indeterminate equilibria are promising vehicles to explain features of the real economy and that by adding a belief function, as I have done here, we may make considerable progress in combining macroeconomics and finance.

\footnotetext{
${ }^{15}$ I thank an anonymous referee for drawing my attention to this point.
} 


\section{Conclusion}

In this paper, I have presented a theory that explains asset pricing data in a new way. In contrast to much of the existing literature in both macroeconomics and finance, my work is based on the idea that most asset price fluctuations are caused by non-fundamental shocks to beliefs. My model produces data that display volatile asset prices and a sizable risk premium. If one accepts the argument that a simpler explanation is a better one, the fact that I am able to reproduce these empirical facts in a model with CRRA preferences and no fundamental shocks suggests that the model is on the right track.

My model is rich in its implications. It provides a simple theory of the pricing kernel that can be used to price other assets. The model is open to more rigorous econometric testing and its parameters can be estimated, rather than calibrated, using non-linear methods. It provides a theory of the term structure of interest rates that can be tested against observed bond yields. By adding a richer theory, in which output fluctuates as a consequence of movements in labor supply or because of movements in the unemployment rate, the theory can be estimated using data from both bond prices and equity markets. I view all of these extensions as grist for the mill of future research. Conducting these extensions is important because my model is not just a positive theory of asset prices; it is ripe with normative implications.

In my baseline calibration, I chose parameters to match key features of the data and I generated simulated data series that closely mimic observed interest rates and asset prices in the real world. In these simulations, asset price fluctuations cause Pareto inefficient re-allocations of wealth between current and future generations and these re-allocations lead to substantial fluctuations in welfare. If my model is correct, and these fluctuations are the main reason why asset prices move in the real world, stabilizing asset prices through monetary and fiscal interventions will be unambiguously welfare improving. 


\section{REFERENCES}

Andrew B. Abel. Asset prices under habit formation and catching up with the joneses. The American Economic Review; Papers and Proceedings, 80(2):38-42, 1990.

Andrew B. Abel, N. Gregory Mankiw, Lawrence H. Summers, and Richard J. Zeckhauser. Assesing dynamic efficiency: Theory and evidence. Review of Economic Studies, 56:1-20, 1989.

Costas Azariadis. Self-fulfilling prophecies. Journal of Economic Theory, 25(3): 380-396, 1981.

Ravi Bansal and Amir Yaron. Risks for the long run: A potential resolution of asset pricing puzzles. The Journal of Finance, 59(4):1481-1509, 2004.

Robert J. Barro. Rare events and the equity premium puzzle. NBER WP 11310, 2005.

Robert J. Barro. Rare disasters and asset markets in the twentieth century. Quartlerly Journal of Economics, 121(3):823-866, 2006.

Olivier J. Blanchard. Debt, deficits, and finite horizons. Journal of Political Economy, 93(April):223-247, 1985.

John Y. Campbell and John H. Cochrane. By force of habit: A consumptionbased explanation of of aggregate stock market behavior. Journal of Political Economy, 107:205-251, 1999.

Dave Cass and Karl Shell. Do sunspots matter? Journal of Political Economy, 91:193-227, 1983.

Edouard Challe. Sunspots and predictable asset returns. Journal of Economic Theory, 115(1):182 - 190, 2004.

Richard Clarida, Jordi Galí, and Mark Gertler. Monetary policy rules and macroeconomic stability: Evidence and some theory. Quarterly Journal of Economics, CXV:147-180, 2000.

John H. Cochrane. Asset Pricing. Princeton University Press, Princeton and Oxford, 2001.

George M. Constantinides. Habit formation: A resolution of the equity premium puzzle. Journal of Political Economy, 98(3):519-543, 1990.

George M. Constantinides and Darrell Duffie. Asset pricing with heterogenous consumers. The Journal of Political Economy, 104(2):219-240, 1996. 
Larry Epstein and Stanley Zin. Substitution, risk aversion and the temporal behavior of consumption and asset returns: An empirical analysis. Journal of Political Economy, 99:263-286, 1989.

Larry Epstein and Stanley Zin. Substitution, risk aversion and the temporal behavior of consumption and asset returns: A theoretical framework. Econometrica, 57:937-969, 1991.

Roger E. A. Farmer. The Macroeconomics of Self-Fulfilling Prophecies. MIT Press, Cambridge, MA, 1993.

Roger E. A. Farmer. Fiscal policy, equity premia, and heterogenous agents. UCLA mimeo, 2002a. Paper presented to the conference: New Developments in Fiscal Policy Analysis, at Universitat Pompeu Fabra, Barcelona May 2002.

Roger E. A. Farmer. Business cycles with heterogenous agents. UCLA mimeo, May 2002b. Paper prepared for a conference at GREQAM on" New Perspectives of (In)Stability, the Role of Heterogeneity", Marseilles, June 2001.

Roger E. A. Farmer. Confidence, crashes and animal spirits. Economic Journal, 122(559), March 2012a.

Roger E. A. Farmer. Animal spirits, persistent unemployment and the belief function. In Roman Frydman and Edmund S. Phelps, editors, Rethinking Expectations: The Way Forward for Macroeconomics, chapter 5, pages 251-276. Princeton University Press, Princeton, NJ, 2012b.

Roger E. A. Farmer. Asset prices in a lifecycle economy. NBER Working Paper Number 19457, 2014.

Roger E. A. Farmer. Global sunspots and asset prices in a monetary economy. NBER Working Paper 20831, 2015.

Roger E. A. Farmer. Pricing assets in an economy with two types of people. NBER Working Paper 22228, 2016.

Roger E. A. Farmer and Giovanni Nicolò. Keynesian economics without the phillips curve. Journal of Economic Dynamics and Control, 2018. forthcoming.

Roger E. A. Farmer and Konstantin Platonov. Animal spirits in a monetary model. NBER Working Paper 22136, 2016.

Roger E A Farmer and Michael Woodford. Self-fulfilling prophecies and the business cycle. Macroeconomic Dynamics, 1(4):740-769, 1997.

Roger E. A. Farmer and Pawel Zabczyk. The theory of unconventional monetary policy. NBER Working Paper no. 22135, March, 2016.

Roger E. A. Farmer, Carine Nourry, and Alain Venditti. Debt deficits and finite horizons, the stochastic case. Economics Letters, 111:47-49, 2011. 
Roger E. A. Farmer, Carine Nourry, and Alain Venditti. The inefficient markets hypothesis: Why financial markets do not work well in the real world. NBER Working Paper 18647, 2012.

Roger E. A. Farmer, Vadim Khramov, and Giovanni Nicolò. Solving and estimating indeterminate DSGE models. Journal of Economic Dynamics and Control., 54:17-36, 2015 .

Zhigang Feng and Matthew Hoelle. Indeterminacy and asset price volatility in stochastic overlapping generations models. Purdue University mimeo, 2014.

Xavier Gabaix. Variable rare disasters: An exactly solved framework for ten puzzles in macro-finance. Quarterly Journal of Economics, 127(2):645-700, 2012 .

Felix R. Gantmacher. Matrix Theory, volume II. AMS Chelsea Publishing, Providence Rhode Island, 2000.

Nicolae Gârleanu and Stavros Panageas. Young, old, conservative, and bold: The implications of heterogeneity and finite lives for asset pricing. Journal of Political Economy, 123(3):670-685, 2015.

Nicolae Gârleanu, Leonid Kogan, and Stavris Panageas. Displacement risk and asset returns. Journal of Financial Economics, 105(3):491 - 510, 2012.

Francois Gourio. Disaster risk and business cycles. American Economic Review, 102(6):2734-2766, 2012.

Fatih Guvenen. A pasimonious macroeconomic model for asset pricing. Econometrica, 77(6):1711-1750, 2009.

Timothy J. Kehoe and David K. Levine. Comparative statics and perfect foresight in infinite horizon economies. Econometrica, 53:433-453, 1985.

Felix Kubler and Karl Schmedders. Lifecycle portfolio choice, the wealth distribution and asset prices. University of Zurich, mimeo, 2011.

Eric M. Leeper. Equilibria under 'active' and 'passive' monetary and fiscal policies. Journal of Monetary Economics, 27(1):129-147, 1991.

Oren Levintal. Fifth order perturbation solution to DSGE models. Journal of Economic Dynamics and Control, 80:1-16, 2017.

Rajnish Mehra and Edward C. Prescott. The equity premium: A puzzle. Journal of Monetary Economics, 15:145-161, 1985.

Jianjun Miao and Pengfei Wang. Asset bubbles and credit constraints. Boston University, 2017. Unpublished mimeo. 
Jianjun Miao, Pengfei Wang, and Zhiwei Xu. A bayesian dynamic stochastic general equilibrium model of stock market bubbles and business cycles. Quantitative Economics, 6:599-635, 2015.

Thomas A. Rietz. The equity risk premium: A solution. Journal of Monetary Economics, 22(1):117-131, 1988.

Thomas J. Sargent and Neil Wallace. 'Rational' expectations, the optimal monetary instrument, and the optimal money supply rule. Journal of Political Economy, 83:241-254, 1975.

Stephanie Schmitt-Grohé and Martin Uribe. Solving dynamic general equilibrium models using a second-order approximation to the policy function. Journal of Economic Dynamics and Control, 28(4):755-775, 2004.

Robert Shiller. Onlinedata source for "Irrational Exuberance". http://www.econ.yale.edu/ shiller/data.htm, 2014.

Christopher A. Sims. Solving linear rational expectations models. Journal of Computational Economics, 20(1-2):1-20, 2001.

Jessica A. Wachter. Can time-varying risk of rare disasters explain aggregate stock market volatility? The Journal of Finance, 68(3):987-1035, 2013.

Michael Woodford. Interest and Prices: Foundations of a Theory of Monetary Policy. Princeton University Press, Princeton, N.J., 2003. 
Appendix A

In an optimum, the budget constraint must hold with equality,

$$
c_{i}^{s}(\varepsilon)=\mu_{i}[1-\mathcal{T}(\varepsilon)]+a_{i}^{s}(\varepsilon)-\pi \mathbb{E}\left[\tilde{Q}\left(\varepsilon, \varepsilon^{\prime}\right) a_{i}^{s}\left(\varepsilon^{\prime}\right)\right] .
$$

From the envelope condition we have that

$$
\frac{\partial v_{i}}{\partial a_{i}^{s}(\varepsilon)}=\frac{\partial u_{i}}{\partial c_{i}^{s}(\varepsilon)} \frac{\partial c_{i}^{s}(\varepsilon)}{\partial a_{i}^{s}(\varepsilon)} \equiv \frac{\partial u_{i}}{\partial c_{i}^{s}(\varepsilon)}
$$

where I have used the fact that, from $(\mathrm{A} 1), c_{i}^{s}(\varepsilon)$ is a linear function of $a_{i}^{s}(\varepsilon)$.

From the Euler equation, using the definition of $u_{i}^{s}$,

$$
\frac{\partial u_{i}}{\partial c_{i}^{s}(\varepsilon)} \frac{\partial c_{i}^{s}(\varepsilon)}{\partial a_{i}^{s}\left(\varepsilon^{\prime}\right)}=\pi \beta_{i} \chi(\varepsilon) \frac{\partial v_{i}}{\partial a_{i}^{s}\left(\varepsilon^{\prime}\right)} .
$$

Using (A1) and (A2) in (A3) and the functional form for utility,

$$
\pi \tilde{Q}\left(\varepsilon, \varepsilon^{\prime}\right) c_{i}^{s}(\varepsilon)^{-\rho_{i}}=\pi \beta_{i} c_{i}^{s}\left(\varepsilon^{\prime}\right)^{-\rho_{i}} .
$$

Rearranging this equation gives

$$
\tilde{Q}\left(\varepsilon, \varepsilon^{\prime}\right)=\beta_{i}\left(\frac{c_{i}^{s}(\varepsilon)}{c_{i}^{s}\left(\varepsilon^{\prime}\right)}\right)^{\rho_{i}}
$$

which is Equation 2 from the solution to Problem 1.

Now conjecture that the policy function takes the form,

$$
X_{i}(\varepsilon) c_{i}^{s}(\varepsilon)=\mu_{i} H(\varepsilon)+a_{i}^{s}(\varepsilon)
$$

where

$$
X_{i}(\varepsilon)=1+\pi \beta_{i}^{\frac{1}{\rho_{i}}} \mathbb{E}\left[\tilde{Q}\left(\varepsilon, \varepsilon^{\prime}\right)^{\frac{\rho_{i}-1}{\rho_{i}}} X_{i}\left(\varepsilon^{\prime}\right)\right]
$$

and

$$
H(\varepsilon)=1-[\tau+(1-\delta) B(\varepsilon)]+\pi \mathbb{E}\left[\tilde{Q}\left(\varepsilon, \varepsilon^{\prime}\right) H\left(\varepsilon^{\prime}\right)\right],
$$

From Equation (A6),

$$
X_{i}\left(\varepsilon^{\prime}\right) c_{i}^{s}\left(\varepsilon^{\prime}\right)=\mu_{i} H\left(\varepsilon^{\prime}\right)+a_{i}^{s}\left(\varepsilon^{\prime}\right) .
$$

Multiplying Equation (A9) by $\pi \tilde{Q}\left(\varepsilon, \varepsilon^{\prime}\right)$, taking expectations and using equations 
(A1) and (A8),

$$
\begin{aligned}
& \pi \mathbb{E}\left[\tilde{Q}\left(\varepsilon, \varepsilon^{\prime}\right) X_{i}\left(\varepsilon^{\prime}\right) c_{i}^{s}\left(\varepsilon^{\prime}\right)\right]= \\
& \pi \mathbb{E}\left[\tilde{Q}\left(\varepsilon, \varepsilon^{\prime}\right) \mu_{i} H\left(\varepsilon^{\prime}\right)\right]+\pi \mathbb{E}\left[\tilde{Q}\left(\varepsilon, \varepsilon^{\prime}\right) a_{i}^{s}\left(\varepsilon^{\prime}\right)\right]
\end{aligned}
$$

Next, replace $c_{i}^{s}\left(\varepsilon^{\prime}\right)$ by $c_{i}^{s}(\varepsilon) \beta_{i}^{\frac{1}{\rho_{i}}} \tilde{Q}\left(\varepsilon, \varepsilon^{\prime}\right)^{\frac{-1}{\rho_{i}}}$ from (A5) and use (A1) and (A8) to give

$$
\begin{aligned}
\pi c_{i}^{s}(\varepsilon) \mathbb{E}\left[\beta_{i}^{\frac{1}{\rho_{i}}} \tilde{Q}\left(\varepsilon, \varepsilon^{\prime}\right)^{\frac{\rho_{i}-1}{\rho_{i}}} X_{i}\left(\varepsilon^{\prime}\right) c_{i}^{s}\left(\varepsilon^{\prime}\right)\right] \\
=\pi \mathbb{E}\left[\tilde{Q}\left(\varepsilon, \varepsilon^{\prime}\right) \mu_{i} H\left(\varepsilon^{\prime}\right)\right]+\pi \mathbb{E}\left[\tilde{Q}\left(\varepsilon, \varepsilon^{\prime}\right) a_{i}^{s}\left(\varepsilon^{\prime}\right)\right] \\
=\mu_{i} H(\varepsilon)+a_{i}^{s}(\varepsilon)-c_{i}^{s}(\varepsilon)=\left[X_{i}(\varepsilon)-1\right] c_{i}^{s}(\varepsilon)
\end{aligned}
$$

where the final equality uses the policy function, Equation (A5).

Cancelling $c_{i}^{s}(\varepsilon)$ from both sides of (A11) and rearranging terms gives

$$
X_{i}(\varepsilon)=1+\pi \mathbb{E}\left[\beta_{i}^{\frac{1}{\rho_{i}}} \tilde{Q}\left(\varepsilon, \varepsilon^{\prime}\right)^{\frac{\rho_{i}-1}{\rho_{i}}} X_{i}\left(\varepsilon^{\prime}\right) c_{i}^{s}\left(\varepsilon^{\prime}\right)\right],
$$

which establishes that the conjectured policy function, (A5) solves Problem 1 when $X_{i}(\varepsilon)$ is given by Equation (A12).

\section{APPENDIX B}

Let $c_{i}^{o}(\varepsilon)$ be the consumption at date $t$ in state $\varepsilon$ of a representative type $i$ person who was alive at date $t-1$ and let $c_{i}^{y}(\varepsilon)$ be the consumption of a representative newborn person of type $i$. Adding up over all people of type $i$, gives

$$
C_{i}(\varepsilon)=\pi c_{i}^{o}(\varepsilon)+(1-\pi) c_{i}^{y}(\varepsilon) .
$$

A person who is alive in two consecutive periods obeys the Euler equation,

$$
c_{i}(\varepsilon) \beta_{i}^{\frac{1}{\rho_{i}}}=c_{i}^{o}\left(\varepsilon^{\prime}\right) \tilde{Q}\left(\varepsilon, \varepsilon^{\prime}\right)^{\frac{1}{\rho_{i}}}
$$

Newborn people consume

$$
c_{i}^{y}\left(\varepsilon^{\prime}\right)=\mu_{i} X_{i}\left(\varepsilon^{\prime}\right)^{-1} H\left(\varepsilon^{\prime}\right),
$$


Aggregating Equation (B2), using (B1).

$$
\tilde{Q}\left(\varepsilon, \varepsilon^{\prime}\right)^{\frac{1}{\rho_{i}}}=\frac{C_{i}(\varepsilon) \pi \beta_{i}^{\frac{1}{\rho_{i}}}}{C_{i}\left(\varepsilon^{\prime}\right)-(1-\pi) X_{i}^{-1} \mu_{i} H\left(\varepsilon^{\prime}\right)},
$$

Using the fact that,

$$
\mu_{i} X_{i}^{-1} H\left(\varepsilon^{\prime}\right)=C_{i}\left(\varepsilon^{\prime}\right)-A_{i}\left(\varepsilon^{\prime}\right),
$$

leads to,

$$
\tilde{Q}\left(\varepsilon, \varepsilon^{\prime}\right)=\left(\frac{C_{i}(\varepsilon) \pi \beta_{i}^{\frac{1}{\rho_{i}}}}{\pi C_{i}\left(\varepsilon^{\prime}\right)+(1-\pi) X_{i}\left(\varepsilon^{\prime}\right)^{-1} A_{i}\left(\varepsilon^{\prime}\right)}\right)^{\rho_{i}}
$$

which is the modified Euler equation. 